\title{
HYDATID CYST WITH FOCUS ON MANIFESTATIONS, DIAGNOSIS, AND MANAGEMENT: REVIEW
}

\author{
KANAAN AL-TAMEEMI ${ }^{1}$, RAIAAN KABAKLI ${ }^{2 *}$
}

${ }^{1}$ Department of Microbiology, Faculty of Pharmacy, Al-Andalus University for Medical Sciences, Tartous, Syria. ${ }^{2}$ Department of Basic Sciences, Faculty of Pharmacy, Al-Andalus University for Medical Sciences, Tartous, Syria. Email: raiaan.youssef@gmail.com

Received: 20 September 2019, Revised and Accepted: 22 October 2019

ABSTRACT

Hydatids or cystic echinococcosis results from being infected with Echinococcus granulosus that found in dogs as definitive hosts and humans, sheep, goats, and pigs as intermediate hosts, mainly prevailing in regions with animal husbandry. Echinococcosis is a public health concern, especially in developing regions; this is due to the medical and economic harm to humans and the inefficiency of treatment and the difficulties of diagnosis in the early stages of infection. Our review summarizes the historical backgrounds of Echinococcus, together with the biological and epidemiological aspects of parasite, in addition to diagnosis and treatment ways.

Keywords: Hydatids, Echinococcosis, Parasite, Granulosus, Hosts.

(C) 2019 The Authors. Published by Innovare Academic Sciences Pvt Ltd. This is an open access article under the CC BY license (http://creativecommons. org/licenses/by/4. 0/) DOI: http://dx.doi.org/10.22159/ajpcr.2019.v12i12.35781

\section{INTRODUCTION}

The first history of hydatids goes back to antiquity, from Hippocrates time (377 BC) who wrote in his scripts (Seventh, 55): "In those whose liver is stuffed with water open into the omentum, the belly is filled with water, and they die" [1,2]. In $200 \mathrm{BC}$, Galen considered the liver as the main site of hydatids in animal's slaughters. Later, the presence of hydatids in animals and humans was reported frequently [2].

Until the early modern age, the true nature of hydatids was still unknown. In 1685, Philip Hartmann emphasized the animal nature of cysticerci when he described a small, spherical structure which was connected with the bladder. Peter Pallas arranged the hydatids as a separated group (bladder worms) and described them in his medical thesis (in 1760) as small bodies located on the inner wall of the bladders. Carl Asmund Rudolphi (1801) introduced the Echinococcus name to zoology [1].

Echinococcus granulosus is distributed worldwide and more frequently in rural areas. The geographic distribution of E. granulosus is variable due to deficiency of accurate case reporting; thus, it is difficult to assign a true specific map of the epidemiologic [3]. In general, there are highly endemic areas in the eastern part of the Mediterranean region, at the southern tip of South America, Southern and Eastern Europe, Northern Africa, in Central Asia, Siberia, and Western China. E. granulosus is restricted to the northern hemisphere, in particular to the regions of China, the Russian Federation, and countries in continental Europe and North America [4].

\section{BIOLOGY OF ECHINOCOCCUS}

The bisexual adult worm consists of four parts: Scolex $(0.3 \mathrm{~mm})$ which contains a rostellum with a double crown of hooklets, four oval suckers, short neck, and one or two of reproductive units (the mature segment with testes and ovary and the gravid segment where the uterus contains about 500 eggs) (Fig. 1) [1,5].

The intermediate host ingests the eggs; these eggs are resistant to external conditions so they are able to remain infective after months outside the body. After ingestion, eggs hatch releasing oncospheres that get through the intestinal wall and carried with blood to different organs of the host, especially liver and lungs [2,6]. After about $12 \mathrm{~h}$ of ingestion, oncosphere arrives at the liver and develops into a hydatid cyst that keeps growing by the time, producing protoscoleces by asexual division. The definitive host becomes infected by eating the meat of the infected intermediate host containing the hydatid cyst. The protoscoleces attach to the villi of the small intestine by their heads and develop to adult worms in 40-50 days. The eggs of E. granulosus are released after separation of a gravid segment that occurs every 2 weeks (Fig. 2) [1,5,7-10]

\section{IMMUNITY RESPONSE BETWEEN THE E. GRANULOSUS AND THE HUMAN}

The host immunity plays an important role in determining the relationship between the host and the parasite. Parasite produces excretory compounds, which influence the immune-competent cells in the human host and stimulate pro-inflammatory immune responses, releasing antibodies, and activate T-cells in the body [1].

Continuing presence of parasites in the body indicates that they have developed some of the evasion mechanisms from host immune mechanisms to preserve their development. E. granulosus can use two mechanisms to reduce the host immune response: (1) Passive escape by developing into a hydatid cyst so avoiding the ruining effects of an immune response and, (2) immunomodulation through which E. granulosus interacts with the host immune system to reduce the efficiency of the host response. Recent studies showed that E. granulosus secretes molecules that can modulate the immune responses so changing the cytokine balance toward Th2 [1,12].

According to epidemiological reports, there is evidence that humans who are infected with Echinococcus multilocularis appear resistant to disease development either by seroconversion or by presenting intrahepatic lesions. The embedding of the metacestode in mightily linked collagens can lead to metacestode death. Antibodies play a major role in parasite killing as a protective immune response against E. granulosus involving antibody-dependent cell-mediated cytotoxicity reactions [13]. Cystic echinococcosis (CE) induces two (Th1 and Th2) cytokine secretion patterns in the active and inactive stages of hydatid disease. Early Th1 cytokine production (which kills the metacestode at the initial stages) changes to a predominant Th2 cytokine as a response in the chronic stage of E. granulosus and E. multilocularis infections [14]. Th2 cells produce interleukin (IL)-4, IL-5, IL-6, and IL-10 which are associated with susceptibility to the disease, whereas Th1 cells express IL-2 and interferon-gamma and they are well related to protective 
immunity. Some of the studies showed an increase in the production of some cytokines such as gamma interferon, IL-4, and IL-5 [15-17].

\section{Symptoms}

The clinical symptoms are changeable and in the early stages are asymptomatic. This is based on the target organ, the size of the hydatid

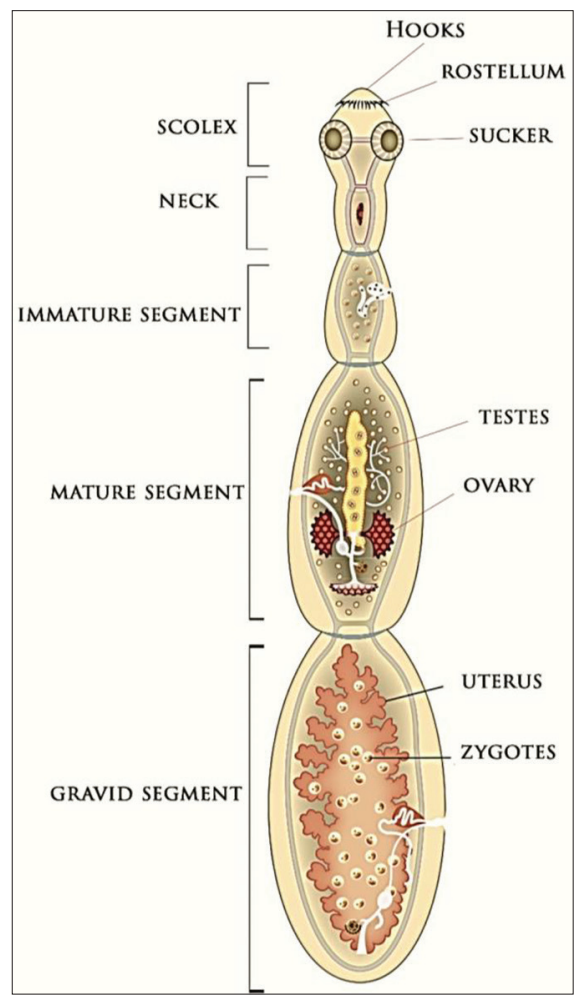

Fig. 1: Morphology of adult worm of Echinococcus granulosus [1] cyst and its site within the organ, the complications of cyst splitting, and protoscoleces spread $[18,19]$.

The symptoms of hepatic echinococcosis include hepatic enlargement, pain, nausea, and vomiting. Although the larval growth in bones is irregular, when it occurs, it causes extensive erosion of the bone [8]. The hydatid cysts can be found in any organ and structure such as abdominal cavities, kidney, bone, brain, ovary, and testis $[20,21]$ and act like tumors that can injure the function of the organ that can be severe, and in some cases deadly. In addition, immunological reactions may be observed such as asthma, anaphylaxis, and urticaria [18].

\section{Diagnosis}

Previously, the diagnosis of echinococcosis was done by inspection and palpation of the distended abdomen or palpable hydatid cyst. In 1877, Neisser affirmed the worth of puncture as a diagnostic way between CE, ascites, ovarian cysts, etc. [1].

The radiography was introduced as a diagnostic technique then followed by angiography, computed tomography, cholangiography, ultrasonography, magnetic resonance imaging, and positron emission tomography (in 1990) [1,22].

Immunodiagnosis tests of echinococcosis in humans are dated back to the beginning of the $20^{\text {th }}$ century such as indirect hemagglutination test, immunoprecipitation, and immunoelectrophoresis, in addition to antibody tests such as indirect fluorescent antibody test and the enzyme-linked immunosorbent assay [1].

\section{Treatment}

The treatment of echinococcosis involves many options depending on the experience of specialists, the availability of abilities, the size, and location of the hydatid cyst and the appearance of complications [23].

The two benzimidazoles (mebendazole and albendazole) are the two most common drugs used for chemotherapy. Patients who have small cysts can be treated successfully with albendazole. About one-third of

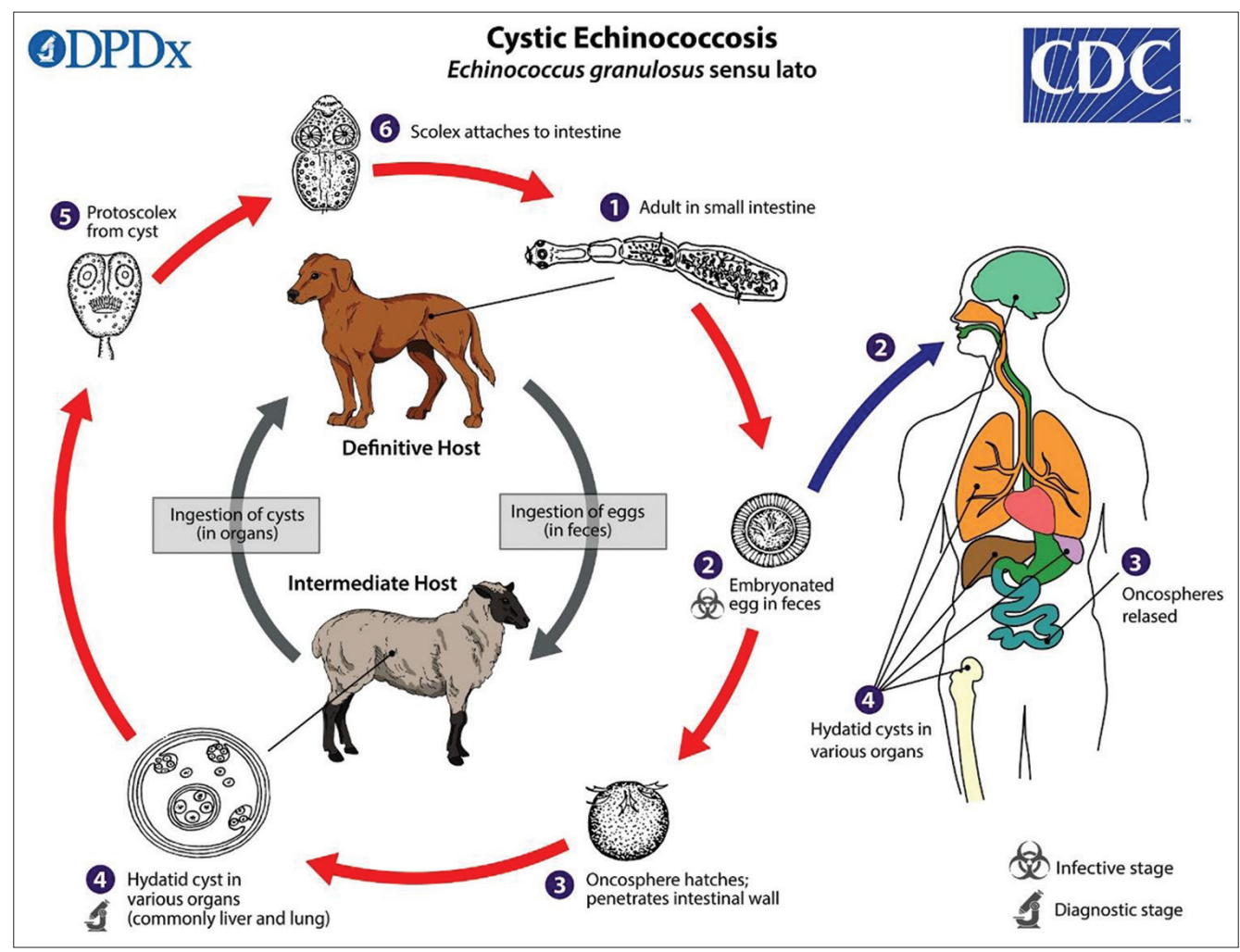

Fig. 2: Life cycle of Echinococcus granulosus [11] 
patients treated with benzimidazole drugs ( $400 \mathrm{mg}$ orally twice a day for 1-6 months) have been cured and about $30-50 \%$ of patients showed downsizing of the cyst and reducing of symptoms. Mebendazole is used as a second choice for treatment $(40-50 \mathrm{mg} / \mathrm{kg}$ body weight per day for several months) $[24,25]$. Praziquantel in combination with albendazole showed very rapid effective results compared with treatment by albendazole alone $[8,26]$. These drugs can be very effective when used in synchronization with surgeries for reducing the relapse after surgery.

Puncture, aspiration, injection, and reaspiration is another treatment choice, which includes the following steps $[1,8,27,28]$ :

- Percutaneous puncture using sonographic guidance

- Aspiration of substantial amounts of hydatid cyst fluid

- Injection of a parasiticidal solution $(20 \%$ sodium chloride or preferably $95 \%$ ethanol) for at least 15 min followed by respiration.

Surgery has played an effective role in the therapy of echinococcosis including cysts removed and liver transplant $[1,9,29]$.

Surgery is the preferred treatment when hydatid cysts are large (e.g., liver hydatid cysts $>10 \mathrm{~cm}$ in diameter) or when they are located in certain organs (e.g., brain, lung, or kidney), but in some cases, surgery becomes ineffective, especially in patients who have multiple cysts and it is so difficult to access [8].

It is worth mentioning that the surgery should be done carefully with avoidance of the adverse effects of leakage of hydatid cyst fluid [30], in addition to use drugs in synchronization with surgeries [25].

\section{Control and prevention}

It is difficult to adjust the exposure to echinococcosis that due to difficulty in staying aloof from CE eggs which are transmitted with feces of wild animals causing recurrence of $\mathrm{CE}$, on the other hand, it's difficulties in diagnosis because the disease in animals is asymptomatic [25,31]. However, control of hydatidosis depends on breaking the cycle of infection either by preventing definitive hosts (as dogs) from eating carcasses of infected intermediate hosts or by preventing intermediate hosts (as humans) from eating contaminant food by dog feces $[7,32]$.

Procedures must be taken to prevent its prevalence:

- Prevent dogs from feeding on infected sheep $[19,33]$

- The limiting of home cattle butchers [34]

- Avoidance of any food or water that may be contaminated by dog's feces $[25,35]$

- Handwashing with soap and water after handling dogs [25]

- Vaccination of cattle with EG95 vaccine to interrupt the life cycle of E. granulosus [36-38]

- Dogs can be terminated using praziquantel every 6 weeks $[37,39]$

- Not to contact with wild animals such as foxes and stray dogs [25].

\section{DISCUSSION}

Echinococcosis is a zoonoses disease that is caused by the larvae of the genus Echinococcus (E. granulosus). The infection of humans occurs through direct contact with the definitive hosts as dogs. The most commonly affected organ is the liver followed by the lungs, while other organs are less affected. It manifests as a slow-growing mass filled with clear fluid. The standard of treatment is based on different surgical techniques with or without chemotherapy. It is very important to understand the immune mechanisms for explaining the protective ways in humans who are infected with hydatidosis and development of more effective vaccines against $E$. granulosus.

\section{CONCLUSIONS}

We concluded from this present review that echinococcosis is a widely endemic disease throughout the world. The wide distribution of this infection that human shares with animals makes the disease one of the most dangerous zoonoses in many parts of the world. It is necessary for reducing the infection complications by the early diagnosis and the urgent need of public awareness of disease and adopting preventive procedures to reduce the spread of the disease.

\section{AUTHORS' CONTRIBUTIONS}

Both authors have contributed for review preparation and editing of the manuscript.

\section{CONFLICTS OF INTEREST}

We declare that there are no conflicts of interest.

\section{REFERENCES}

1. Thompson RC, Deplazes P, Lymbery AJ. Advances in Parasitology. Amsterdam: Elsevier Ltd; 2017.

2. Slimane NN, Taieb M, Khiali R, Rabehi H, Bekhouche R, Bendjaballah A. A huge primary hydatid cyst of uterus: A case report and review of literature. J Univer Surg 2018;6:12.

3. Available from: https://www.cdc.gov/dpdx/echinococcosis/index.html.

4. Available from: https://www.who.int/echinococcosis/epidemiology/en/.

5. Rahman WA, Elmajdoub LE, Noor SA, Wajidi MF. Present status on the taxonomy and morphology of Echinococcus granulosus: A review. Austin J Vet Sci Anim Husb 2015;2:1013.

6. Morar S, Dura H, Cristian A, Perju-Dumbravă D, Boicean A, CernuşcăMițariu M, et al. Hydatid cyst a rare etiology of sudden death. Case report and literature review. Rom J Leg Med 2014;22:31-4.

7. Mohamed M, Wafa I, Kawther I, Annajar BB. Incidence and the history of Echinococcus granulosus infection in dogs within the past few decades in Libya: A review. J Vet Med Anim Health 2017;9:1-10.

8. Moro P, Schantz PM. Echinococcosis: A review. Int J Infect Dis 2009; $13: 125-33$

9. Bekçi TT. diagnosis and treatment of human hydatid disease. Eur J Gen Med 2012;9 (Suppl 1):15-20.

10. Tse C, Bullard J, Rusk R, Douma D, Plourde PJ. Surveillance of Echinococcus tapeworm in coyotes and domestic dogs in Winnipeg, Manitoba: Abstract. Can Commun Dis Rep 2019;45:171-6.

11. Available from: https://www.cdc.gov/parasites/echinococcosis/biology. html.

12. Siracusano A, Delunardo F, Teggi A, Ortona E. Cystic echinococcosis: Aspects of immune response, immunopathogenesis and immune evasion from the human host. Endocr Metab Immune Disord Drug Targets 2012;12:16-23.

13. Zhang W, Wen H, Li J, Lin R, McManus DP. Immunology and immunodiagnosis of cystic echinococcosis: An update. Clin Dev Immunol 2012;2012:101895.

14. Zhang W, Ross AG, McManus DP. Mechanisms of immunity in hydatid disease: Implications for vaccine development. J Immunol 2008; 181:6679-85.

15. Bayraktar MR, Mehmet N, Durmaz R. Th1 and Th2 inducing cytokines in cystic echinococcosis. Turkiye Parazitol Derg 2005;29:167-70.

16. Grubor NM, Jovanova-Nesic KD, Shoenfeld Y. Liver cystic echinococcosis and human host immune and autoimmune follow-up: A review. World J Hepatol 2017;9:1176-89.

17. Kakkos1 SK, Mouzaki A, Vagianos CE. Modifications of the immune system caused by the cestode. Echinococcus granulosus: A review. Ann Gastroenterol 2001;14:91-8.

18. Eckert J, Gemmell MA, Meslin FX, Pawłowski ZS. WHO/OIE Manual on Echinococcosis in Humans and Animals: A Public Health Problem of Global Concern. Geneva: World Health Organization; 2002.

19. Mahmoudvand H, Taee N, Kheirandish F, Nadri S, Goudarzi MF, Shahkarami S. Seroprevalence and risk factors of cystic echinococcosis among children in Lorestan province, Western Iran. J Res Med Dent Sci 2018;6:88-92.

20. Eckert J, Gemmell MA, Meslin FX, Pawłowski ZS, editors. WHO/OIE Manual on Echinococcosis in Humans and Animals: A Public Health Problem of Global Concern. Paris, France: World Organization for Animal Health; 2001.

21. Ammann RW, Eckert J. Cestodes. Echinococcus. Gastroenterol Clin North Am 1996;25:655-89.

22. Aydin Y, Altuntas B, Kaya A, Ulas AB, Uyanık MH, Eroglu A, et al. The availability of Echinococcus igG ELISA for diagnosing pulmonary hydatid cysts. Eurasian J Med 2018;50:144-7.

23. Higuita N, Brunetti E, McCloskey C, Cystic echinococcosis. J Clin Microbiol 2016;54:518-23.

24. Almasri B, Albitar L. Rare isolated primary peritoneal hydatid cysts: A case report from Syria. Qatar Med J 2016;2016:13. 
25. Available from: https://www.cdc.gov/parasites/echinococcosis/health professionals/index.html\#tx. [Last accessed on 2019 Aug].

26. Cobo F, Yarnoz C, Sesma B, Fraile P, Aizcorbe M, Trujillo R, et al. Albendazole plus praziquantel versus albendazole alone as a pre-operative treatment in intra-abdominal hydatisosis caused by Echinococcus granulosus. Trop Med Int Health 1998;3:462-6.

27. Gonzalez A, Gomez-Puerta L. Echinococcus. Switzerland: CSpringer International Publishing AG; 2018.

28. World Health Organization. PAIR: Puncture Aspiration, Injection, ReAspiration, An Option for the Treatment of Cystic Echinococcosis. Geneva: World Health Organization; 2001.

29. Aghajanzadeh M, Hassanzadeh R, Rimaz S, Hemmati H, Delshad MS, Rad AM. Management and outcome of complicated liver hydatid cysts. Clin Surg 2017;2:1820.

30. Bhutani N, Kajal P. Hepatic echinococcosis: A review. Ann Med Surg (Lond) 2018;36:99-105.

31. Velasco-Tirado V, Romero-Alegría Á, Belhassen-García M, AlonsoSardón M, Esteban-Velasco C, López-Bernús A, et al. Recurrence of cystic echinococcosis in an endemic area: A retrospective study. BMC Infect Dis 2017;17:455.

32. Mandal S, Mandal MD. Human cystic echinococcosis: Epidemiologic, zoonotic, clinical, diagnostic and therapeutic aspects. Asian Pac J Trop
Med 2012;5:253-60.

33. Abdulhameed MF, Habib I, Al-Azizz SA, Robertson I. Knowledge, awareness and practices regarding cystic echinococcosis among livestock farmers in Basrah province, Iraq. Vet Sci 2018;5:E17.

34. Torgerson PR. Helminth-cestode: Echinococcus granulosus and Echinococcus multilocular, Zurich open repository and archive. In: Motarjemi Y, editors. Encyclopedia of Food Safety. Waltham, MA: Elsevier; 2014.

35. Ministry of Health. Ministry of Health and Long-Term Care, Appendix A: Disease-Specific Chapters. New Delhi: Ministry of Health; 2019.

36. Morariu S, Lightowlers MW, Cosoroabă I, Dărăbuș G, Bart JM, Ilie M, et al, Utilization of EG95 vaccine for sheep immunization against cystic echinococcosis in Romania. Sci Parasitol 2010;11:29-34.

37. Craig PS, Hegglinx D, Lightowlers MW, Torgerson P, Wang Q. Echinococcosis: Control and Prevention, Advances in Parasitology. Vol. 95. Netherlands: Elsevier Ltd; 2017.

38. Gauci C, Heath D, Chow C, Lightowlers MW. Hydatid disease: Vaccinology and development of the EG95 recombinant vaccine. Expert Rev Vaccines 2005;4:103-12.

39. Jiang B, Zhou XN, Zhang HB, Tao Y, Huo LL, Liu N, et al. Slowrelease praziquantel for dogs: Presentation of a new formulation for echinococcosis control. Infect Dis Poverty 2017;6:140. 